\title{
Researching COVID-19 tracing app acceptance: Incorporating theory from the technological acceptance model
}

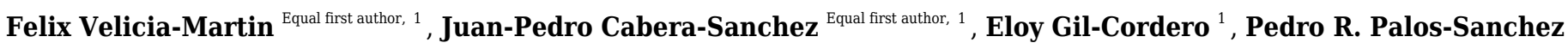 \\ Corresp. 2 \\ ${ }^{1}$ Department Business Administration and Marketing, University of Sevilla, Sevilla, Spain \\ 2 Department Financial Economy and Operations Research, University of Sevilla, Sevilla, Spain \\ Corresponding Author: Pedro R. Palos-Sanchez \\ Email address: ppalos@us.es
}

Background: The expansion of the coronavirus pandemic and the extraordinary confinement measures imposed by governments have caused an unprecedented intense and rapid contraction of the global economy. In order to revive the economy, people must be able to move safely, which means that governments must be able to quickly detect positive cases and track their potential contacts. Different alternatives have been suggested for carrying out this tracking process, one of which uses a mobile APP which has already been shown to be an effective method in some countries.

Objective: Use an extended TAM (Technology Acceptance Model) model to investigate whether citizens would be willing to accept and adopt a mobile application that indicates if they have been in contact with people infected with COVID-19. Research Methodology: A survey method was used and the information from 482 of these questionnaires was analyzed using PLS-SEM (Partial Least Squares-Structural Equation Modelling).

Results: The results show that the Intention to Use this app would be determined by the Perceived Utility of the app and that any user apprehension about possible loss of Privacy would not be a significant handicap. When having to choose between health and privacy, users choose health.

Conclusions: This study shows that the extended TAM model which was used has a high explanatory power. Users believe that the APP is useful (especially users who studied in higher education), that it is easy to use, and that it is not a cause of concern for privacy. The highest acceptance of the app is found in over 35 years old's, which is the group that is most aware of the possibility of being affected by COVID-19. The information is unbelievably valuable for developers and governments as users would be willing to use the APP. 
1 Researching COVID-19 tracing app acceptance:

2 Incorporating theory from the technological

3 acceptance model

4

5

Felix Velicia-Martin ${ }^{1}$, Juan Pedro Cabrera-Sánchez ${ }^{1}$, Eloy Gil-Cordero and Pedro R. PalosSanchez ${ }^{2}$

7

8

${ }^{1}$ Department Business Administration and Marketing, University of Sevilla, Sevilla, Spain

${ }^{2}$ Department Financial Economy and Operations Research, University of Sevilla, Sevilla, Spain 10

Corresponding Author:

12 Pedro R. Palos-Sanchez ${ }^{2}$

13 Facultad de Ciencias Económicas y Empresariales.

14 Av. Ramon y Cajal, 1, Sevilla, 41018, Spain

15 Email address: ppalos@us.es

16

\section{Abstract}

Background. The expansion of the coronavirus pandemic and the extraordinary confinement measures imposed by governments have caused an unprecedented intense and rapid contraction of the global economy. In order to revive the economy, people must be able to move safely, which means that governments must be able to quickly detect positive cases and track their potential contacts. Different alternatives have been suggested for carrying out this tracking process, one of which uses a mobile application or APP which has already been shown to be an effective method in some countries.

Objective. Use an extended TAM (Technology Acceptance Model) model to investigate whether citizens would be willing to accept and adopt a mobile application that indicates if they have been in contact with people infected with COVID-19.

Methods. A survey method was used and the information from 482 of these questionnaires was analyzed using PLS-SEM (Partial Least Squares-Structural Equation Modelling).

Results. The results show that the Intention to Use this app would be determined by the Perceived Utility of the app and that any user apprehension about possible loss of Privacy would not be a significant handicap. When having to choose between health and privacy, users choose health. Conclusions. This study shows that the extended technology acceptance model TAM model which was used has a high explanatory power. Users believe that the APP is useful (especially users who studied in higher education), that it is easy to use, and that it is not a cause of concern for privacy. The highest acceptance of the app is found in over 35 years old, which is the group that is most aware of the possibility of being affected by COVID-19. The information is unbelievably valuable for developers and governments as users would be willing to use the APP. 
40

41

42

43

44

45

46

47

48

49

50

51

52

53

54

55

56

57

58

59

60

61

62

63

64

65

66

67

68

69

70

71

72

73

74

75

76

77

78

79

Keywords COVID-19, TAM, Privacy, APP, Technology Adoption

\section{Introduction}

The new coronavirus (COVID-19) pandemic started in December 2019 in Wuhan City [1], is different to the coronavirus cases previously written about in the literature, such as Middle East Respiratory Syndrome (MERS) or Severe Acute Respiratory Syndrome (SARS) [2]. This difference is due to the COVID-19 being highly infectious, which led to a rapid increase in new cases and a worldwide outbreak [3]. This situation meant that strong quarantine rules were imposed in large cities, towns, and public areas around the world to prevent further spread [4]. COVID-19 poses unprecedented challenges to governments and societies around the world [5].

The recommendations for isolation and mobility limitation by the World Health Organization (WHO) have been an effective strategy in containing and mitigating the spread rate of infection

[6]. This has allowed more time to prepare for the next phases of the pandemic and avoid the saturation of health systems.

The confinement strategy has led to almost a complete shutdown of global economic activity. This will result in an unprecedented economic crisis over the coming quarters. In January 2020, before the COVID-19 pandemic, the growth forecast for the Global Economy in 2020 stood at 2.5\% (World Bank, 2020), with the International Monetary Fund being more optimistic with forecasts of $3.3 \%$ growth. After just a few days of confinement, new economic forecasts which took the pandemic into account appeared in April 2020. The World Bank forecast a 4\% contraction in the Global Economy [7]. In the United States, the gross domestic product (GDP) decreased at an annual rate of 5.0 percent in the first quarter of 2020 [8]. In the same way, the forecasts for the European Union in 2020 are terrifying both for GDP growth (-7.4\%), unemployment $(9.0 \%)$ and gross public debt $(95.1 \%)$.

Disaster risk managers require technological support to make complex decisions when faced with a crisis [9]. Different ways of monitoring positive COVID-19 cases are emerging, in order to assist national and international mobility. Governments throughout the world have proposed different ways of doing this, such as the use of "immunity passports" [10], the inclusion of blockchain technology to ensure monitoring in different areas [11], the use of "Smart Cities" to implement artificial intelligence in order to monitor positive cases [12], the use of APPs to inform citizens about other positive cases in their area [13]. This last solution is the case that will be studied in this investigation. Previous research has used APP to monitor health problems, such as hypertension [14]. It was first implemented in South Korea and Israel using geolocation technology.

Recently, in Europe, the French government launched the STOP COVID app which uses Bluetooth technology [15] instead of geolocation and is used voluntarily.

The governments of other countries, such as Singapore, also adopted a voluntary installation regime for the app and launched a strong marketing campaign. However, the app penetration rate remained below $25 \%$ two weeks after the launch [13]. In the case of Spain, the state of alarm 
80 decreed by the government in March 2020 included tracking mobile devices to monitor physical 81 contacts, a measure which meant a reduction in the right to privacy for health reasons. The apps 82 that are currently available or being developed can be grouped into four categories: a) Self83 diagnosis apps, b) Chatbots or conversational assistants which will provide information to citizens, 84 c) Mobility apps which supply anonymous data to databases in order to track the evolution of the 85 disease and d) Apps such as those planned for in Pan-European Privacy-Preserving Proximity 86 Tracing (PEPP-PT) in which the APP detects the proximity of other potentially infected citizens, 87 while keeping the information anonymous.

88 This study investigates apps in category d) above which have been recommended by the European 89 Commission in various Decisions and Directives [16] since Apps that help give warnings are the 90 most promising for preventing the spread of the virus.

91 The most relevant APPs have been compiled by [17] and we must emphasize that some of them 92 already have more than two million downloads such as the APP developed in UK (NHS APP), 93 Australia (COVIDsafe), Israel (The Shield), Singapore (TraceTogether) or Spain (Radar COVID).

94 Therefore, some governments are considering using apps that monitor infected people and their 95 environment [18]. One of the main problems of this is the personal information that the user 96 provides, which includes age, sex, height, weight and zip code, in addition to listing any chronic 97 health conditions, such as heart, lung or kidney diseases, diabetes and the regular use of immune 98 suppressants [19].

99 Because a large majority of users are willing to use this type of APP [20], this means that the

100

101

102

103

104

105

106

107

108

109

110

111

112

113

114

115

116

117 COVID-19 APP

118 Tracking positive cases of COVID-19 using APPs is useful for citizens because users can take 119 factors which indicate the intention to use and adoption of this type of app by future users must be investigated. The main objective of this study is to answer the question "What are the factors that affect whether the users will be willing to use an APP that would alert them if they have been in contact with anybody infected with COVID?"

This means that the factors which indicate the intention to use and adoption of this type of app by future users must be investigated. The main objective of this study is to answer the question "Would users be willing to use an APP that would alert them if they have been in contact with anybody infected with COVID?"

This study is structured in the following way: after this introduction, the proposed model will be justified, and the hypotheses will be formulated. The third section will explain the data collection process, identifying how each of the variables studied was measured, as well as identifying the software used in the analysis. The data and results are analyzed in paragraph 4, where the hypotheses raised in paragraph 2 are verified. Paragraph 5 presents the conclusions drawn, together with limitations of the study and possible future research.

\section{Literature Review}

precautions before going out of their houses [18]. This type of APP has many different uses, one 
120

121

122

123

124

125

126

127

128

129

130

131

132

133

134

135

136

137

138

139

140

141

142

143

144

145

146

147

148

149

150

151

152

153

154

155

156

157

158

159

of which is controlling the epidemic without blocking the movement of citizens and the resulting economic damage [21]. For this reason, this study analyzes the different factors which can influence the acceptance of an app by the population.

\section{Technology acceptance model (TAM)}

The technological acceptance model (TAM) proposed by Davis [22], [23] is used for this study as it is widely accepted by the researchers in the literature review [24]-[27]. TAM is based on two primary variables, which are 1) independent variables that include Perceived Usefulness and Perceived Ease of Use and, 2) the dependent variable Attitude Towards Use. Davis [28] defined Perceived Usefulness as the degree to which a person believes that using a system will improve their performance, and defined Perceived Ease of Use as the degree to which a person believes that using a system is effortless. In addition, Davis [29] noted that the actual use of the system is determined by behavioral intention of the user, and this intention is determined jointly by the attitude of users towards the use of the system and its perceived usefulness [30]. This study uses an extended TAM model, which is the original TAM model with added variables, such as Trust [31], [32], Perceived Risk [33], which in this case is the perceived risk of catching the COVID-19 virus, and finally, privacy concerns [34], [35].

The TAM with some updates was selected because apart from being a widely contrasted model, it has also been used to evaluate the intention of use of APPs in different sectors and circumstances[36]-[38].

\section{Research model and hypotheses development}

\section{Technology acceptance and behavioral intention}

COVID-19 has led to an unprecedented global crisis which has had many casualties, caused economic losses and disrupted daily activities [39]. This is why many governments are considering allowing economic and social movement in the next phases of the pandemic, with innovative solutions such as using APPs to provide information to the population. Despite the recognized potential of Information Technology (IT) for health issues [40], [41], most IT-based health systems encounter user resistance [42], and reduced intention to use them. Therefore, the behavioral intention of users must be investigated using a technology acceptance model to find what influences the Intention to Use this App. This study uses the Technology Acceptance Model extended with health-related variables, as used by Hu, Griffin, \& Bertuleit [43].

\section{Attitude Towards Using}

Attitude Towards Using is defined in the TAM model as the how a user feels about using the technology being studied [29]. Research can be found in academic literature for APPs that supports 
160 the relationship of the variables stated above using the TAM model [44] with health applications 161 [45].

162 Thus, we can formulate the following hypothesis:

163 Hypothesis 1: The Attitude Towards Using an APP positively affects Behavioral Intention to Use 164 it.

165

166

167

168

169

170

171

172

173

174

175

176

177

178

179

180

181

182

183

184

185

186

187

188

189

190

191

192

193

194

195

196

197

198

199

200

\section{Perceived risk of catching COVID-19}

The perceived risk of catching COVID-19 has been adapted from the research by [46]. In general, the importance of risk in predicting human behavior cannot be denied. Perceived risk is defined as a how uncertain a person feels when deciding whether to do something or not [47]. Perceived risk is a crucial variable for evaluating user acceptance of an APP in this study. The literature states that perceived risk contributes to expectations of negative consequences, which has a negative effect on intention to use [48].

Thus, we can formulate the following hypothesis:

Hypothesis 2: The Perceived Risk of getting COVID-19 positively affects the Behavioral Intention to Use an APP.

\section{Ease of Use and Perceived Usefulness}

The first studies using TAM to investigate public health information systems and APPS, found that Ease of Use and Perceived Usefulness were the most common and significant determinants of technology acceptance [49]-[51]. Perceived Usefulness is defined as the extent to which a person believes that using a system will help improve performance [28]. Ease of Use is defined as the degree to which a person believes that the use of technology will require minimal effort [52]. This study expects to find that the population will accept and use this type of APP because advantages can be gained by using it. The TAM model states that the attitude towards using any technological system is determined by the two variables, Perceived Usefulness and Perceived Ease of Use of the system [53].

Thus, we can formulate the following hypothesis:

Hypothesis 3: The Perceived Ease of Use of the APP positively affects Attitude towards Using it. Hypothesis 4: The Perceived Ease of Use of the APP positively affects its Perceived Usefulness. Hypothesis 5: The Perceived Usefulness of the APP positively affects Attitude Towards Using it. Hypothesis 6: The Perceived Usefulness of the APP positively affects the Behavioral Intention to Use.

\section{Privacy}

Privacy has been used in various previous studies as an extension to the TAM model [54], [55]. It can be defined for health APPs as how safe a user feels that the personal health information shared 
201

202

203

204

205

206

207

208

209

210

211

212

213

214

215

216

217

218

219

220

221

222

223

224

225

226

227

228

229

230

231

232

233

234

235

236

237

238

239

with a technological system, in this case an APP, will only be used for the stated purpose and not shared with others [42]. In previous studies[56], privacy has been shown to be a determining factor for the acceptance of technology [57]. The importance of privacy, when it comes to sharing medical information, cannot be denied. Therefore, users who are concerned about the privacy of sharing their personal information with a health APP may be reluctant to adopt it.

Thus, we can formulate the following hypothesis:

Hypothesis 7: Privacy Concern with an APP negatively affects the Behavioral Intention to Use it.

\section{Trust}

Previous studies have included external factors such as trust in theoretical TAM models to explain the acceptance of APPs in different areas including medical services [36], [58], [59]. Trust has been defined as the faith of users/patients that the services provided by a new technology will have positive results [42]. This study analyzes users' trust in the use of APP technological to increase their intention to use APPs that use geolocation for the COVID-19 virus.

Thus, we can formulate the following hypothesis:

Hypothesis 8: Trust in an APP positively affects the Behavioral Intention to Use it

Figure 1 shows the proposed research model using the hypotheses given above.

Figure 1: proposed research model

\section{Materials \& Methods}

A sample of 482 possible users of the APP was used to investigate the proposed hypotheses. The surveys were written an online form which was distributed online, by email and on social networks. Previous to this phase, an initial test survey had been carried out with researchers and potential users in order to check the survey and questions and detect any possible errors.

Table 1: sample obtained $(n=482)$

The demographic grouping of the sample is shown in Table 1, and an interesting point which was noted is that there were 164 possible users between 15 and 30 years, 122 between 31 and 45 years and 196 over 46 years. The original measurement scales for the variables included in TAM, proposed by Davis [23], were adapted for this study, as were those of Son \& Kim [60] for Privacy Concern, Pavlou \& Gefen [61] for Trust, and Napper, Fisher \& Reynolds [46] for COVID. Scales used are shown in Annex 1. All variables have been measured with a seven-point Likert scale. The complete model was tested with Partial Least Squares (PLS), technique for analyzing complex relationships between latent variables that allows explaining the observed data and predictive 
240 analysis as a relevant element in scientific research, which was applied using SmartPLS-3 software 241 [62].

242

\section{Results}

244 The reliability and validity of the measurement model was tested analyzing Cronbach's Alpha, 245 and Composite Reliability, which meant that the latent variables needed to have a minimum value 246 of 0.7 to be acceptable [63]. Table 2 shows that the values obtained for the measurement model 247 meet these requirements. The reliability of the constructs can be seen to be acceptable, as the values

248 of composite reliability and Cronbach's Alpha pass the minimum required value of 0.7 [64] and 249 the value for the average variance extracted (AVE) exceeds 0.5 [65].

250 The values shown in Table 3 were used check the discriminatory validity of the model and the 251 constructs. The Fornell and Larcker [66] test was used, in which where the square root of the AVE 252 of each latent variable was compared with that of all the other variables [67].

253

254

Table 2: composite reliability and convergent validity

255

256

Table 3: Fornell and Larcker test

257

258

Table 4 shows the values used to test the structural model using the path coefficients. The 259 resampling technique called bootstrapping with 5000 test cycles was used to check which

260

261

262 relationships were significant.

263

264

265

Table 4: Structural model test (path coefficients)

266

267

Some indirect effects of the relationships between the main constructs were noted and are shown in Table 5.

268

269

Table 5: indirect effects

270

The results for the model show that it has high explanatory power. This can be seen from the results shown in Table 6 for the values found for R-squared of the second-order constructs, especially 271 Behavior Intention. In both cases of R-squared and adjusted R-squared the values are higher than 272 the recommended value of 0.1 [68]. According to Chin [69], a value of 0.67 indicates high 273 explanatory power, 0.33 indicates moderate explanatory power and 0.19 indicates weak 274 explanatory power. The results can be seen in Table 6 and show that the value for Behavioral 275 Intention (R-squared=0.769) and the other variables are all much higher than the minimum level 276 indicating high indicatory power.

277

278 Table 6: values of R-squared for the model

279 
280 The fit of the model was then checked using the values of the Standardized Root Mean Square 281 Residual (SRMR), which had a value of 0.039 which was much less than the maximum 282 recommended limit for a good fit of 0.08 [63]. Finally, the values for the Stone-Geisser $\mathrm{Q}^{2}$ of the 283 model [70] were used to evaluate its predictive power. The values obtained for $\mathrm{Q}^{2}$ were greater 284 than 0 [71], which shows that the model has predictive power. The values obtained are shown in 285 Table 7

286

287

288

289

290

291

292

293

294

295

296

297

298

299

300

301

302

303

304

305

306

307

308

309

310

311

312

313

314

315

316

317

318

319

Table 7: predictive power of latent variables

Table 8 shows the results of a multigroup analysis with PLS-MGA using permutations [72]. The moderating effects of the classification and sociodemographic variables presented in Table 1 were analyzed using this multigroup analysis [73] in order to test the potential moderating influence of gender, level of education and employment on the relationships in the research model. The sample was divided into groups using these variables and the measurement invariance of the composite model was found (MICOM) [74].

Table 8: Multigroup Analysis MGA

\section{Discussion, conclusions and limitations}

\section{Discussion}

Extended TAM can be seen to be a useful model for predicting intention to use a new APP that allows people who have been in contact with a positive COVID-19 case to be tracked and thus help break the chain of infection. Not only have the hypotheses of the original TAM model been met, but the model with the added variables has a higher predictive power. Hypotheses H1 Attitude $\square$ Behavioral Intention $(\beta=0.461 ; t=7.323)$, H4 Perceived Ease of Use $\rightarrow$ Perceived Usefulness $(\beta=0.846 ; t=53.406)$ and H5 Perceived Usefulness $\rightarrow$ Attitude $(\beta=0.703 ; t=16.994)$ have the highest factor loading. These hypotheses are from the original TAM model, together with H3 Perceived Ease of Use $\rightarrow$ Attitude $(\beta=0.224 ; \mathrm{t}=4.951)$ y H6 Perceived Usefulness $\rightarrow$ Behavioral Intention $(\beta=0.293 ; \mathrm{t}=4.395)$ which are also from the original model. The analysis showed that they have a confidence level above $99.9 \%$. This means that the theoretical TAM model can be used to investigate the adoption of apps to prevent and mitigate the effects of the COVID-19 pandemic.

The variables that contribute the most to the model are Perceived Ease of Use $(\beta=0.846 ; \mathrm{t}=$ 53.406) and Perceived Usefulness $(\beta=0.703 ; \mathrm{t}=16.994)$, followed by Attitude $(\beta=0.461 ; \mathrm{t}=$ 7.323). These results coincide with another recent study using the extended TAM model [75].

The relationship for the external variable which directly influenced Behavioral Intention to Use was H8 ( $\beta=0.461 ; t=7.323$ ) which was supported with a confidence level above $99.9 \%$. This means that the users of the app trust it to keep its promises, meet the expectations the users have, and also take into account the interests of users as citizens and members of a community. These three items significantly condition the intention to try using the app in daily life. 
320 The results for the external variables which were added to the original TAM model for this study

321

322

323

324

325

326

327

328

329

330

331

332

333

334

335

336

337

338

339

340

341

342

343

344

345

346

347

348

349

350

351

352

353

354

355

356

357

358

of COVID PR were then analyzed. The variables were included in $\mathrm{H} 2$ and gave the results PR COVID $\rightarrow$ Behavioral Intention to use $(\beta=0.078 ; t=3.589)$. The relationship was confirmed and with a confidence level of more than $99.9 \%$. It can therefore be seen that users' concerns about being infected or that family members are infected with COVID-19 decisively influences the intention to use the app. Users are also concerned about becoming vulnerable to COVID-19 infection. These concerns along with the feeling of vulnerability, added to the information about the high rates of COVID-19 infection, all strongly influence the intention to try out and continue to use this app frequently in the future.

The last external variable proposed for the model Privacy Concern was not significant and only had $95 \%$ confidence level. Thus, H7 Privacy Concern $\square$ Behavioral Intention to use ( $\beta=0.002$; $=0.087$ ) was not significant. This means that the concern about information in the app being used inappropriately, as in other person using private information in an unforeseen manner, does not negatively influence the intention to try out and continue to use the app frequently in the future. This result has been seen in previous studies on app adoption models and can be found in the literature [76].

The extended variable that most influences the user's decision is Trust, followed by PR COVID. In both cases, the higher the trust, or the greater the perceived risk, the greater the intention to use the APP.

The multigroup analysis showed the results did not vary for Age in H2, PR COVID $\rightarrow$ Behavioral Intention (95\%) and $\mathrm{H} 7$ Privacy Concern $\rightarrow$ Behavioral Intention (95\%). $\mathrm{H} 2$ found that the relationship is not significant in young people $<35$ years old. $\mathrm{H} 7$ showed that there was a greater concern for privacy, which had a more negative influence on young people $<35$ years old. However, this was not significant in either group. Level of Education was found to moderate H6 Perceived Usefulness $\rightarrow$ Behavioral Intention, with $99.9 \%$ confidence level, and this relationship is only significant for users with higher education. H8 Trust $\rightarrow$ Behavioral Intention (95\%) is also influenced by Level of Education and the relationship is strongest for users with lower levels of education.

Type of employment moderated the relationships of H7 Privacy Concern $\rightarrow$ Behavioral Intention (95\%) and H8 Trust $\rightarrow$ Behavioral Intention. For H7, Privacy Concern was higher in contracted and self-employed workers and housewives than in students, pensioners or the unemployed. This means that employment conditions this relationship, although the relationship was not found to be significant for any of the groups. H8 Trust $\rightarrow$ Behavioral Intention (99\%) was not found to be significant for the group on account of type of employment.

It is worth noting the high explanatory power of the Behavioral Intention to Use model $\left(\mathrm{R}^{2}=\right.$ $0.769)$ and other variables such as Attitude $\left(R^{2}=0.769\right)$ and Perceived Usefulness $(R 2=0.716)$, as well as its predictive capacity Behavioral Intention to Use $\left(\mathrm{Q}^{2}=0.636\right)$.

\section{Conclusions about theory}


359

360

361

362

363

364

365

366

367

368

369

370

371

372

373

374

375

376

377

378

379

380

381

382

383

384

385

386

387

388

389

390

391

392

393

394

395

396

397

398

399

The theoretical TAM adoption model was extended in order to improve its predictive power [36], [77] and to adapt it to this new technology, as well as applying it in the exceptional case of a pandemic. All the new variables, except Privacy Concern, contributed to the model and improved the investigation results. An extended TAM model is proposed to explain the adoption of information systems and geolocation technology to combat the main means of virus propagation, which is contact between people less than two meters apart.

It was also found that the population could be persuaded to adopt this app and give up privacy, although problems could occur, not only with the loss of privacy, but also increased alerts on devices or incompatibility of the app in different countries.

The main novelty of this research is related to privacy. While other authors have focused on the privacy of the APP itself [78] or how to maintain people's privacy [79], our research shows that people do not care about privacy when it comes to health issues. We have also extended the TAM with a new variable for the first time that is PRCOVID or perceived risk to be infected with COVID-19. This new variable has been significant and has improve the explanation power of the TAM .

\section{Practical conclusions}

The expansion of COVID-19 has led to a pandemic with millions of infected people and thousands of deaths worldwide. The adoption of extraordinary confinement measures by many governments has slowed the rapid pace of contagion and enabled health systems to care for the sick. This confinement has caused an unprecedented contraction in the global economy. Faced with this, population and pressure groups are demanding faster de-escalation processes. In order to revive the economy, people need to move, and health authorities must be able to detect positive cases early, as well as track their potential contacts. Different methods have been proposed for this tracking, including the use of mobile apps [17].

The economy has been gravely damaged, although the balance of health and economy must be tilted in favor of the former. Therefore, tracking technologies should be used in the de-escalation processes to increase the safety of the population and be able to isolate new positive cases and their contacts.

This type technology of has been useful in countries like South Korea, which has managed to deescalate quickly and safely, therefore reactivating its economy thanks to apps using geolocation technology [13], [80].

The study results show that the intention to use this app is determined by its Perceived Usefulness, especially in the case of users with higher education levels [81], [82], and that the concern for a possible loss of Privacy is not significant [83]. When choosing between health and privacy, the user chooses health.

This information will be very valuable for app developers using geolocation and also for governments, who take the decision about its use and the loss of privacy that this implies. There have not been many cases of this loss of rights, albeit on a temporary basis, in Europe's contemporary history. Governments may find it extremely useful to know that users over the age

Peer) Comput. Sci. reviewing PDF | (CS-2020:07:50721:2:1:NEW 19 Oct 2020) 
400 of 35 are most concerned about infection of themselves or family members and this has a decisive 401 influence on their intention to use the app. The feeling of being vulnerable to infection by the 402 COVID-19 virus also influencers the user intention. Therefore, both the concern and the feeling of 403 vulnerability added to the perception of a high chance of infection by COVID-19 exert a noticeable 404 influence on the intention to try this app and frequently use it. These results support recent studies 405 [13] which showed that $75 \%$ of respondents in the UK would install the app. These authors found 406 strong support for the use of the type of app that was investigated in this study, in four major 407 European countries, which implies a possible pan-European app with data roaming in different 408 countries. Decisions about launching this app must be made urgently and no time can be lost. Most 409 importantly, the user must feel that it is a useful measure (especially for users with higher levels 410 of education), easy to use, is respectful with information and, above all, does not cause concerns 411 for privacy. This study therefore supports the fact that users would be willing to use this app if 412 they trust it (especially employed users) and value its usefulness, respectful attitude and ease of use, and concern for privacy would not significantly influence the intention to use it.

\section{References}

[1] V. Fidan, "New type of corona virus induced acute otitis media in adult," Am. J. Otolaryngol., p. 102487, 2020.

[2] Q. Li, X. Guan, P. Wu, X. Wang, L. Zhou, Y. Tong, ... and Xing, "Early transmission dynamics in Wuhan, China, of novel coronavirus--infected pneumonia," N. Engl. J. Med., 2020.

[3] P. Mo, Y.Xing, Y. Xiao, L. Deng, Q. Zhao, H. Wang,... and M. Luo, “Clinical characteristics of refractory COVID-19 pneumonia in Wuhan, China," Clin. Infect. Dis., 2020.

[4] A. S. R. S. Rao and J. A. Vazquez, "Identification of COVID-19 can be quicker through artificial intelligence framework using a mobile phone--based survey when cities and towns are under quarantine," Infect. Control Hosp. Epidemiol., vol. 41, no. 7, pp. 826830, 2020.

[5] M. Chinazzi, J.T. Davis, M. Ajelli, C. Gioannini, M. Litvinova, S. Merler, ... and C.Viboud, "The effect of travel restrictions on the spread of the 2019 novel coronavirus (COVID-19) outbreak," Science (80-. )., vol. 368, no. 6489, pp. 395-400, 2020.

[6] S. K. Brooks et al., "The psychological impact of quarantine and how to reduce it: rapid review of the evidence," Lancet, 2020.

[7] M. Maliszewska, A. Mattoo, and D. Van Der Mensbrugghe, "The potential impact of COVID-19 on GDP and trade: A preliminary assessment." The World Bank, 2020.

[8] Bureau of Economic Analysis, "Bureau of Economic Analysis," 2020. [Online]. Available: https:/www.bea.gov/news/2020/gross-domestic-product-1st-quarter-2020-secondestimate-corporate-profits-1 st-quarter.

[9] N. Kourti et al., "Strategies for improving Urban Resilience in Europe," 2019. 
443 [10] C. M. Angelopoulos, A. Damianou, and V. Katos, "DHP Framework: Digital Health

444

445

446

447

448

449

450

451

452

453

454

455

456

457

458

459

460

461

462

463

464

465

466

467

468

469

470

471

472

473

474

475

476

477

478

479

480

481

482

483

484

485

486

487

488
Passports Using Blockchain," arXiv Prepr. arXiv2005.08922, 2020.

[11] D. Nguyen, M. Ding, P. N. Pathirana, and A. Seneviratne, "Blockchain and AI-based Solutions to Combat Coronavirus (COVID-19)-like Epidemics: A Survey," 2020.

[12] Z. Allam and D. S. Jones, "On the coronavirus (COVID-19) outbreak and the smart city network: universal data sharing standards coupled with artificial intelligence (AI) to benefit urban health monitoring and management," in Healthcare, 2020, vol. 8, no. 1, p. 46.

[13] J. Abeler, S. Altmann, L. Milsom, S. Toussaert, and H. Zillessen, "Support in the UK for app-based contact tracing of COVID-19." 2020.

[14] R. M. A. Ortega, A. I. O. Jiménez, J. M. S. Perea, E. S. Cuadrado, and A. M. S. López, "Nutritional patterns on prevention and control of hypertension," Nutr. Hosp., vol. 33, no. Suppl 4, p. 347, 2016.

[15] L. R. Bradford, M. Aboy, and K. Liddell, "COVID-19 Contact Tracing Apps: A Stress Test for Privacy, the GDPR and Data Protection Regimes," J. Law Biosci., 2020.

[16] Across Legal Marketing, "Recomendaciones de la Unión Europea para las Apps sobre COVID 19," 2020. [Online]. Available: https://acrosslegal.com/recomendacion-europeapara-las-apps-del-covid-19/.

[17] J. LI and X. Guo, "Global Deployment Mappings and Challenges of Contact-tracing Apps for COVID-19," SSRN Electron. J., 2020.

[18] S. Altmann et al., "Acceptability of app-based contact tracing for COVID-19: Crosscountry survey evidence," Available SSRN 3590505, 2020.

[19] S. Mayor, "Covid-19: Researchers launch app to track spread of symptoms in the UK." British Medical Journal Publishing Group, 2020.

[20] K. Kaspar, "Motivations for Social Distancing and App Use as Complementary Measures to Combat the COVID-19 Pandemic: Quantitative Survey Study," J. Med. Internet Res., vol. 22, no. 8, p. e21613, 2020.

[21] L. Ferretti et al., "Quantifying SARS-CoV-2 transmission suggests epidemic control with digital contact tracing," Science (80-. )., vol. 368, no. 6491, 2020.

[22] F. Davis, "A Technology Acceptance Model for Empirically Testing New End-User Information Systems," Massachusetts Inst. Technol., no. December 1985, p. 291, 1985.

[23] F. D. Davis, R. P. . Bagozzi, and P. R. . Warshaw, "User Acceptance of Computer Technology: A Comparison of Two Theoretical Models," vol. 35, no. 8, pp. 982-1003, 1989.

[24] B. Szajna, "Empirical evaluation of the revised technology acceptance model," Manage. Sci., vol. 42, no. 1, pp. 85-92, 1996.

[25] S. Hong, J. Y. L. Thong, and K. Y. Tam, "Understanding continued information technology usage behavior: A comparison of three models in the context of mobile internet," Decis. Support Syst., vol. 42, no. 3, pp. 1819-1834, 2006.

[26] W. R. King and J. He, "A meta-analysis of the technology acceptance model," Inf. Manag., vol. 43, no. 6, pp. 740-755, 2006.

[27] C. Evans, R. Hackney, R. Rauniar, G. Rawski, J. Yang, and B. Johnson, "Technology acceptance model (TAM) and social media usage: an empirical study on Facebook," J. Enterp. Inf. Manag., 2014.

[28] F. Davis, "Perceived usefulness, perceived ease of use, and user acceptance of information technology," MIS Q., vol. 13, no. 3, pp. 319-340, 1989.

[29] F. D. Davis, R. P. Bagozzi, and P. R. Warshaw, "Extrinsic and Intrinsic Motivation to Use 
489

490

491

492

493

494

495

496

497

498

499

500

501

502

503

504

505

506

507

508

509

510

511

512

513

514

515

516

517

518

519

520

521

522

523

524

525

526

527

528

529

530

531

532

533

534
Computers in the Workplace," J. Appl. Soc. Psychol., vol. 22, no. 14, pp. 1111-1132, 1992.

[30] Z. Y. Liu, "An Analysis of Technology Acceptance Model-Exploring user acceptance and intension of taxi-hailing app in Shanghai," 2015.

[31] D. Gefen, E. Karahanna, and D. W. Straub, "Trust and TAM in online shopping: An integrated model," MIS Q., vol. 27, no. 1, pp. 51-90, 2003.

[32] I. L. Wu and J. L. Chen, "An extension of Trust and TAM model with TPB in the initial adoption of on-line tax: An empirical study," Int. J. Hum. Comput. Stud., vol. 62, no. 6, pp. 784-808, 2005.

[33] M. C. Lee, "Factors influencing the adoption of internet banking: An integration of TAM and TPB with perceived risk and perceived benefit," Electron. Commer. Res. Appl., vol. 8, no. 3, pp. 130-141, 2009.

[34] T. Zhou, "The impact of privacy concern on user adoption of location-based services," Ind. Manag. Data Syst., vol. 111, no. 2, pp. 212-226, 2011.

[35] P. R. Palos-Sanchez, J. M. Hernandez-Mogollon, and A. M. Campon-Cerro, "The behavioral response to location based services: an examination of the influence of social and environmental benefits, and privacy," Sustainability, vol. 9, no. 11, p. 1988, 2017.

[36] F. Munoz-Leiva, S. Climent-Climent, and F. Liébana-Cabanillas, "Determinants of intention to use the mobile banking apps: An extension of the classic TAM model," Spanish J. Mark., vol. 21, no. 1, pp. 25-38, 2017.

[37] C. Chen, G. Z. de Rubens, X. Xu, and J. Li, "Coronavirus comes home? Energy use, home energy management, and the social-psychological factors of COVID-19," Energy Res. Soc. Sci., p. 101688, 2020.

[38] A. Yuesti, I. G. Ayu Asri Pramesti, and Y. Verawati, "Interests of Individual Taxpayers Using E-Filing for Tax Reporting during the pandemic Covid-19.," Talent Dev. Excell., vol. 12, no. 1, 2020.

[39] A. Remuzzi and G. Remuzzi, "COVID-19 and Italy: what next?," Lancet, 2020.

[40] N. Mattheos et al., "Potential of information technology in dental education," Eur. J. Dent. Educ., vol. 12, pp. 85-92, 2008.

[41] M. B. Buntin, M. F. Burke, M. C. Hoaglin, and D. Blumenthal, "The benefits of health information technology: a review of the recent literature shows predominantly positive results," Health Aff., vol. 30, no. 3, pp. 464-471, 2011.

[42] S. A. Kamal, M. Shafiq, and P. Kakria, "Investigating acceptance of telemedicine services through an extended technology acceptance model (TAM)," Technol. Soc., vol. 60, no. March 2019, p. 101212, 2020.

[43] X. Hu, M. A. Griffin, and M. Bertuleit, "Modelling antecedents of safety compliance: Incorporating theory from the technological acceptance model," Saf. Sci., vol. 87, pp. 292298, 2016.

[44] H. C. Yang and L. Zhou, "Extending TPB and TAM to mobile viral marketing: An exploratory study on American young consumers' mobile viral marketing attitude, intent and behavior," J. Targeting, Meas. Anal. Mark., vol. 19, no. 2, pp. 85-98, 2011.

[45] J. Cho, "The impact of post-adoption beliefs on the continued use of health apps," Int. J. Med. Inform., vol. 87, pp. 75-83, 2016.

[46] L. E. Napper, D. G. Fisher, and G. L. Reynolds, "Development of the perceived risk of HIV scale," AIDS Behav., vol. 16, no. 4, pp. 1075-1083, 2012.

[47] A. I. Nicolaou and D. H. McKnight, "Perceived information quality in data exchanges: Effects on risk, trust, and intention to use," Inf. Syst. Res., vol. 17, no. 4, pp. 332-351, 2006. 
535

536

537

538

539

540

541

542

543

544

545

546

547

548

549

550

551

552

553

554

555

556

557

558

559

560

561

562

563

564

565

566

567

568

569

570

571

572

573

574

575

576

577

578

579

580
[48] P.-J. Hsieh, "An empirical investigation of patients' acceptance and resistance toward the health cloud: The dual factor perspective," Comput. Human Behav., vol. 63, pp. 959-969, 2016.

[49] K. Cho et al., "Learning Phrase Representations using RNN Encoder-Decoder for Statistical Machine Translation," 2014.

[50] P. Whitten, G. Doolittle, and M. Mackert, "Providers' acceptance of telehospice," J. Palliat. Med., vol. 8, no. 4, pp. 730-735, 2005.

[51] I. N. Olver and S. Selva-Nayagam, "Evaluation of a telemedicine link between Darwin and Adelaide to facilitate cancer management," Telemed. J., vol. 6, no. 2, pp. 213-218, 2000.

[52] A. M. Elkaseh, K. W. Wong, and C. C. Fung, "Perceived ease of use and perceived usefulness of social media for e-learning in Libyan higher education: A structural equation modeling analysis," Int. J. Inf. Educ. Technol., vol. 6, no. 3, p. 192, 2016.

[53] M. J. Sánchez Franco, F. A. Martín Velicia, and Á. F. Villarejo Ramos, "El modelo TAM y la enseñanza superior. Una investigación del efecto moderador del sexo," Rev. española Pedagog., pp. 459-478, 2007.

[54] T. Zhou, "The impact of privacy concern on user adoption of location-based services," Ind. Manag. Data Syst., vol. 111, no. 2, pp. 212-226, 2011.

[55] P. Ambrose and C. Basu, "Interpreting the Impact of Perceived Privacy and Security Concerns in Patients' Use of Online Health Information Systems," J. Inf. Priv. Secur., vol. 8, no. 1, pp. 38-50, 2012.

[56] P. Palos-Sanchez, J. R. Saura, and F. Martin-Velicia, "A study of the effects of programmatic advertising on users' concerns about privacy overtime," J. Bus. Res., vol. 96, pp. 61-72, 2019.

[57] C. A. Lin and T. Kim, "Predicting user response to sponsored advertising on social media via the technology acceptance model," Comput. Human Behav., vol. 64, pp. 710-718, 2016.

[58] A. D. Beldad and S. M. Hegner, "Expanding the technology acceptance model with the inclusion of trust, social influence, and health valuation to determine the predictors of German users' willingness to continue using a fitness app: A structural equation modeling approach,” Int. J. Human--Computer Interact., vol. 34, no. 9, pp. 882-893, 2018.

[59] N. M. Suki and N. M. Suki, "Flight ticket booking app on mobile devices: Examining the determinants of individual intention to use," J. Air Transp. Manag., vol. 62, pp. 146-154, 2017.

[60] J.-Y. Y. Son and S. S. Kim, "Internet users' information privacy-protective responses: A taxonomy and a nomological model," MIS Q., vol. 32, no. 3, pp. 503-529, 2008.

[61] P. A. Pavlou and D. Gefen, "Building Effective Online Marketplaces with Institution-Based Trust," Inf. Syst. Res., vol. 15, no. 1, pp. 37-59, Mar. 2004.

[62] C. M. Ringle, S. Wende, and J. M. Becker, "SmartPLS." "SmartPLS 3." Boenningstedt: SmartPLS GmbH, 2015.

[63] J. Henseler, T. K. Dijkstra, M. Sarstedt, C.M. Ringle, A. Diamantopoulos, D.W. Straub, ... and R.J. Calantone, "Common beliefs and reality about PLS: Comments on Ronkko and Evermann (2013)," Organ. Res. Methods, vol. 17, no. 2, pp. 182-209, 2014.

[64] J. C. Nunnally, Psychometric Theory, 2nd ed. MCGraw- Hill College, 1978.

[65] D. Straub, M. Boudreau, and D. Gefen, "Validation Guidelines for IS Positivist," Commun. Assoc. Inf. Syst., vol. 13, pp. 380-427, 2004.

[66] C. M. Ringle, M. Sarstedt, and D. Straub, "A critical look at the use of PLS-SEM in MIS Quarterly,” MIS Q., vol. 36, no. 1, pp. iii-xiv, 2012. 
581

582

583

584

585

586

587

588

589

590

591

592

593

594

595

596

597

598

599

600

601

602

603

604

605

606

607

608

609

610

611

612

613

614

615

616

617

618

619

620

621

622

623

624

625

626

[67] D. Barclay, R. Thompson, and C. Higgins, "The Partial Least Squares (PLS) Approach to Causal Modeling: Personal Computer Adoption and Uses as an Ilustration," Technology Studies, vol. 2, no. 2. pp. 285-309, 1995.

[68] R. F. Falk and N. B. Miller, A Primer for Soft Modeling. University of Akron Press. Akron, Ohio (USA), 1992.

[69] W. W. Chin, "The Partial Least Squares aproach to Structural Equation Modeling," Mod. Methods Bus. Res., pp. 295-336, 1998.

[70] D. Gefen, E. E. Rigdon, and D. Straub, “An Update and Extension to SEM Guidelines for Administrative and Social Science Research.," MIS Q., vol. 35, no. 2, pp. iii-A7, 2011.

[71] J. L. Roldán and M. J. Sánchez-Franco, Variance-Based Structural Equation Modeling: Guidelines for Using Partial Least Squares in Information Systems Research. 2012.

[72] W. W. Chin and J. Dibbern, "An introduction to a permutation based procedure for multigroup PLS analysis: Results of tests of differences on simulated data and a cross cultural analysis of the sourcing of information system services between Germany and the USA," in Handbook of partial least squares, Springer, 2010, pp. 171-193.

[73] J. Henseler, "PLS-MGA: A non-parametric approach to partial least squares-based multigroup analysis," in Challenges at the interface of data analysis, computer science, and optimization, Springer, 2012, pp. 495-501.

[74] J. Henseler, C. M. Ringle, and M. Sarstedt, "Testing measurement invariance of composites using partial least squares," Int. Mark. Rev., vol. 33, no. 3, pp. 405-431, 2016.

[75] J. R. Saura, P. Palos-Sanchez, and F. Velicia-Martin, "What Drives Volunteers to Accept a Digital Platform That Supports NGO Projects?,” Front. Psychol., vol. 11, p. 429, 2020.

[76] P. R. Palos-Sanchez, M. B. Correia, and J. R. Saura, "An empirical examination of adoption of mobile applications in Spain and Portugal, based in UTAUT," Int. J. Mob. Commun., vol. 17, no. 5, pp. 579-603, 2019.

[77] C. D. Melas, L. A. Zampetakis, A. Dimopoulou, and V. Moustakis, "Modeling the acceptance of clinical information systems among hospital medical staff: an extended TAM model," J. Biomed. Inform., vol. 44, no. 4, pp. 553-564, 2011.

[78] J. K. Liu, M. H. Au, T. H. Yuen, C. Zuo, J. Wang, A. Sakzad, ... and L. Li, "PrivacyPreserving COVID-19 Contact Tracing App: A Zero-Knowledge Proof Approach.," IACR Cryptol. ePrint Arch., vol. 2020, p. 528, 2020.

[79] T. M. Yasaka, B. M. Lehrich, and R. Sahyouni, "Peer-to-Peer contact tracing: development of a privacy-preserving smartphone app," JMIR mHealth uHealth, vol. 8, no. 4, p. e18936, 2020.

[80] A. De Carli, M. Franco, A. Gassmann, C. Killer, B. Rodrigues, E. Scheid, ... and B. Stiller "WeTrace--A Privacy-preserving Mobile COVID-19 Tracing Approach and Application," arXiv Prepr. arXiv2004.08812, 2020.

[81] C. E. Porter and N. Donthu, "Using the technology acceptance model to explain how attitudes determine Internet usage: The role of perceived access barriers and demographics," J. Bus. Res., vol. 59, no. 9, pp. 999-1007, 2006.

[82] D. Kucukusta, R. Law, A. Besbes, and P. Legohérel, "Re-examining perceived usefulness and ease of use in online booking," Int. J. Contemp. Hosp. Manag., 2015.

[83] E. D. Madyatmadja, H. Nindito, and D. Pristinella, "Citizen Attitude: Potential Impact of Social Media Based Government," in Proceedings of the 2019 3rd International Conference on Education and E-Learning, 2019, pp. 128-134. 
627

628

629

630

631

632

633

634

635

636

637

638

639

640

641

642

643

644

645

646

647

648

649

650

651

652

653

654

655

656

657

658

659

660

661

\section{Annex 1: proposed scales for the model}

PRCOV1: What is your opinion of the likelihood of you or a family member becoming infected with COVID-19 (extremely unlikely, very unlikely, somewhat likely, very likely, extremely likely)?

PRCOV2: I am worried about getting infected or my family members getting infected with COVID-19 (No time, Rarely, Sometimes, A moderate amount of time, A lot of time, All the time). PRCOV 7: I feel that we may be vulnerable to COVID-19 infection.

PRCOV 9: I think the chances of us getting infected with COVID-19 are very high: (Zero, almost zero, small, moderate, large, very large).

BI1: I intend to continue using this App in the future.

BI2: I will try to use this App in my daily life.

BI3: I intend to continue to use this App frequently.

PC1: I am concerned that information from the APP may be used inappropriately.

PC2: I am concerned that someone else may find out private information about me.

PC3: I am concerned that the information provided to the App may be used by other persons or companies.

PC4: I am concerned about providing personal information to the App service provider because it could be used in a way that is not intended.

TRU1: This App gives me confidence.

TRU2: This App will keep its promises.

TRU3: This App would take into account the interests of the citizens.

AU1: Its use would be positive for my life.

AU2: Its use would be beneficial to my family and circle of friends.

AU3: Its use would be beneficial to society.

PU1: Using this App would make me feel better about myself.

PU2: By using this App I would hope to be helping society.

PU3: The use of this App would increase my peace of mind.

PEOU1: Its purpose is clear and understandable.

PEOU2: I think that learning to use the App would be very easy for me.

PEOU3: With this App, it would be easy for me to avoid the contagion of COVID-19.

PEOU4: I would find it useful to have an App that tells me how to avoid people who have the disease.

PEOU5 The existence of this App would make it easier for me to be aware of the health problem.

PeerJ Comput. Sci. reviewing PDF | (CS-2020:07:50721:2:1:NEW 19 Oct 2020) 
Figure 1

high resolution

Figure changed for other with high resolution

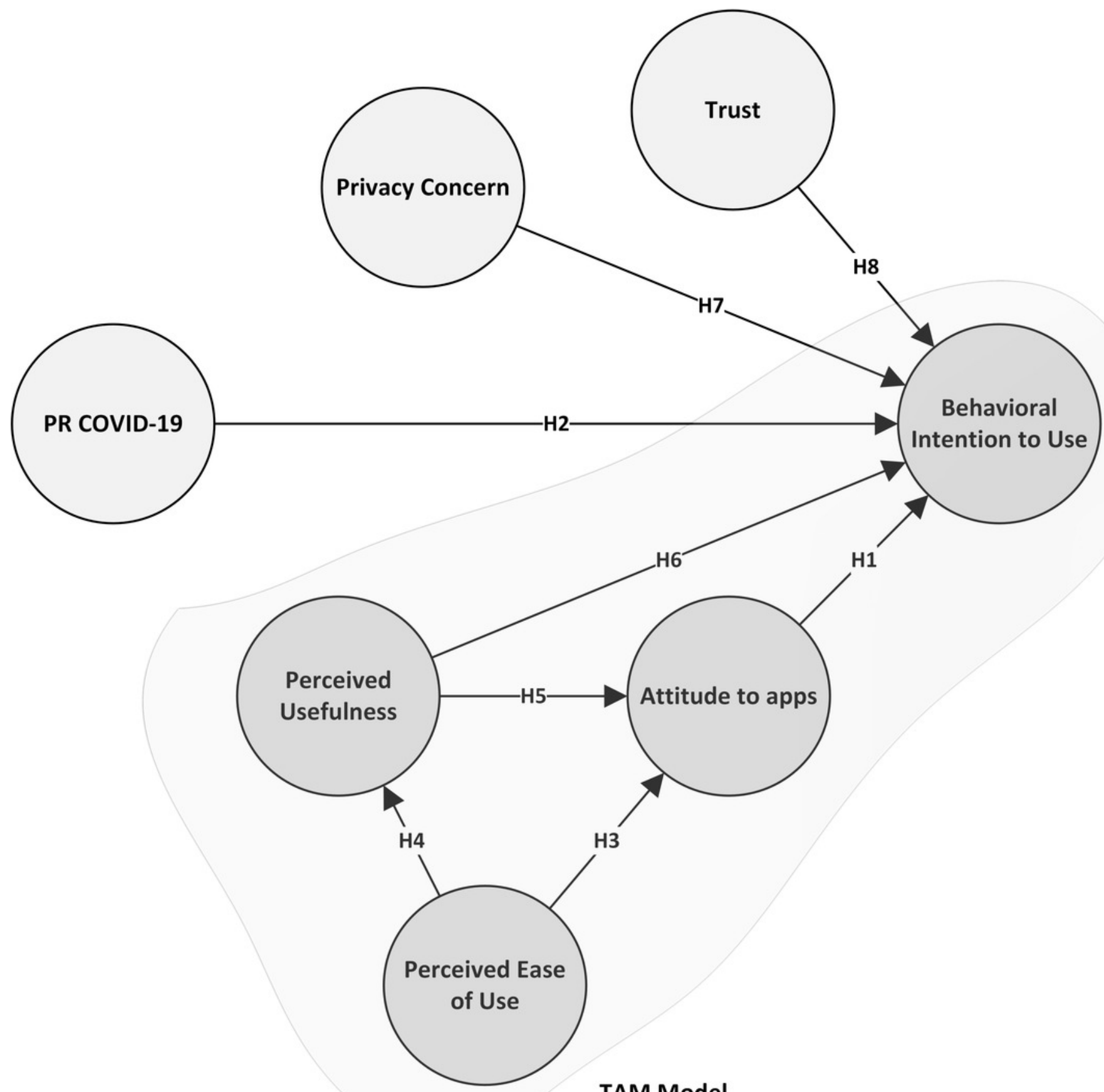

TAM Model 


\section{Table 1 (on next page)}

Table 1: sample obtained $(n=482)$ 
Table 1: sample obtained $(n=482)$

\begin{tabular}{|l|r|r|}
\hline Variable & Frequency & $\mathbf{\%}$ \\
\hline Gender & 211 & $43.78 \%$ \\
\hline Male & 271 & $56.22 \%$ \\
\hline Female & & \\
\hline Habitat & 50 & $10.37 \%$ \\
\hline Between 10.000 and & 57 & $11.83 \%$ \\
Between 20.000 and & 52 & $10.79 \%$ \\
Between 50.000 and & 272 & $56.43 \%$ \\
More than 100.000 & 51 & $10.58 \%$ \\
Less than 10.000 & & \\
\hline Job & 16 & $3.32 \%$ \\
\hline Stay-at-home parent & 124 & $25.73 \%$ \\
Student & 27 & $5.60 \%$ \\
Pensioner & 28 & $5.81 \%$ \\
Unemployed & 246 & $51.04 \%$ \\
Employed & 41 & $8.51 \%$ \\
Self employed & & \\
\hline Marital Status & 226 & $46.89 \%$ \\
\hline Married & 20 & $4.15 \%$ \\
Divorced & 4 & $0.83 \%$ \\
Separated & 200 & $41.49 \%$ \\
Single & 8 & $1.66 \%$ \\
Widower & 24 & $4.98 \%$ \\
Living together & & \\
\hline Education Level & 120 & $24.90 \%$ \\
\hline Post-Graduate & 10 & $2.07 \%$ \\
Primary & 154 & $31.95 \%$ \\
Secondary & 1 & $0.21 \%$ \\
No schooling & 197 & $40.87 \%$ \\
\hline Higher & & \\
\hline Age & 164 & $34.03 \%$ \\
\hline Between 15-30 years & 122 & $25.31 \%$ \\
Between 31-45 years & 196 & $40.66 \%$ \\
\hline 46 years & & \\
\hline
\end{tabular}




\section{Table 2 (on next page)}

Table 2: composite reliability and convergent validity 
Table 2: composite reliability and convergent validity

\begin{tabular}{|c|c|c|c|c|c|}
\hline & & Items & Cronbach's Alpha & Composite Reliability & $\begin{array}{l}\text { Average Variance } \\
\text { Extracted (AVE) }\end{array}$ \\
\hline \multirow{3}{*}{ Attitude } & AU1 & 0.957 & \multirow{4}{*}{0.961} & \multirow{4}{*}{0.975} & \multirow{4}{*}{0.928} \\
\hline & AU2 & 0.975 & & & \\
\hline & AU3 & 0.958 & & & \\
\hline \multirow{4}{*}{$\begin{array}{l}\text { Behavioral } \\
\text { Intention }\end{array}$} & BI1 & 0.962 & & & \\
\hline & BI2 & 0.967 & \multirow[t]{3}{*}{0.964} & \multirow[t]{3}{*}{0.977} & \multirow[t]{3}{*}{0.933} \\
\hline & B13 & 0.968 & & & \\
\hline & PC1 & 0.891 & & & \\
\hline \multirow{4}{*}{ Privacy Concern } & PC2 & 0.906 & \multirow{4}{*}{0.934} & \multirow{4}{*}{0.938} & \multirow{4}{*}{0.834} \\
\hline & PC3 & 0.937 & & & \\
\hline & PC4 & 0.913 & & & \\
\hline & PEOU3 & 0.890 & & & \\
\hline \multirow{3}{*}{$\begin{array}{l}\text { Perceived Ease of } \\
\text { Use }\end{array}$} & PEOU4 & 0.916 & \multirow[t]{3}{*}{0.891} & \multirow[t]{3}{*}{0.925} & \multirow[t]{3}{*}{0.755} \\
\hline & PEOU5 & 0.897 & & & \\
\hline & PRCOV2 & 0.826 & & & \\
\hline \multirow[t]{2}{*}{ PR COVID } & PRCOV7 & 0.879 & \multirow[t]{3}{*}{0.759} & \multirow[t]{3}{*}{0.861} & \multirow[t]{2}{*}{0.675} \\
\hline & PRCOV9 & 0.756 & & & \\
\hline \multirow{4}{*}{$\begin{array}{l}\text { Perceived } \\
\text { Usefulness }\end{array}$} & PU1 & 0.885 & & & \\
\hline & PU2 & 0.914 & \multirow[t]{3}{*}{0.896} & \multirow[t]{3}{*}{0.935} & \multirow[t]{3}{*}{0.828} \\
\hline & PU3 & 0.930 & & & \\
\hline & TRU1 & 0.907 & & & \\
\hline \multirow[t]{2}{*}{ Trust } & TRU2 & 0.910 & \multirow[t]{2}{*}{0.901} & \multirow[t]{2}{*}{0.938} & \multirow[t]{2}{*}{0.834} \\
\hline & TRU3 & 0.922 & & & \\
\hline
\end{tabular}

2 


\section{Table 3(on next page)}

Table 3: Fornell and Larcker test 
1

Table 3: Fornell and Larcker test

\begin{tabular}{|l|l|l|l|l|l|l|l|}
\hline & \multicolumn{1}{|l|}{ AT } & BIU & $\begin{array}{l}\text { PR } \\
\text { COVID }\end{array}$ & PEOU & PU & PC & TR \\
\hline Attitude & 0.963 & & & & & & \\
\hline $\begin{array}{l}\text { Behavioral } \\
\text { Intention }\end{array}$ & 0.854 & 0.966 & & & & & \\
\hline PR COVID & 0.298 & 0.332 & 0.821 & & & & \\
\hline $\begin{array}{l}\text { Perceived } \\
\text { Ease of Use }\end{array}$ & 0.844 & 0.794 & 0.294 & 0.901 & & & \\
\hline $\begin{array}{l}\text { Perceived } \\
\text { Usefulness }\end{array}$ & 0.893 & 0.835 & 0.282 & 0.846 & 0.910 & & \\
\hline $\begin{array}{l}\text { Privacy } \\
\text { Concern }\end{array}$ & -0.097 & -0.081 & 0.198 & -0.078 & -0.070 & 0.912 & \\
\hline Trust & 0.745 & 0.725 & 0.235 & 0.696 & 0.748 & -0.227 & 0.913 \\
\hline
\end{tabular}

2 


\section{Table 4 (on next page)}

Table 4: Structural model test (path coefficients) 
1

Table 4: Structural model test (path coefficients)

\begin{tabular}{|l|l|l|c|c|}
\hline \multicolumn{2}{|l|}{ Hypothesis } & Path $(\beta)$ & t-statistic & p-value \\
\hline 1 & Attitude $\rightarrow$ Behavioral Intention & 0.461 & 7.323 & 0.000 \\
\hline 2 & PR COVID $\rightarrow$ Behavioral Intention & 0.078 & 3.589 & 0.000 \\
\hline 3 & Perceived Ease of Use $\rightarrow$ Attitude & 0.224 & 4.951 & 0.000 \\
\hline 4 & Perceived Ease of Use $\rightarrow$ Perceived Usefulness & 0.846 & 53.406 & 0.000 \\
\hline 5 & Perceived Usefulness $\rightarrow$ Attitude & 0.703 & 16.994 & 0.000 \\
\hline 6 & & & & \\
& Perceived Usefulness $\rightarrow$ Behavioral Intention & 0.293 & 4.395 & 0.000 \\
\hline 7 & Privacy Concern $\rightarrow$ Behavioral Intention & 0.002 & 0.087 & 0.930 \\
\hline 8 & Trust -> Behavioral Intention & 0.145 & 3.510 & 0.000 \\
\hline
\end{tabular}

3 


\section{Table 5 (on next page)}

Table 5: indirect effects 
1

Table 5: indirect effects

\begin{tabular}{|l|r|r|r|}
\hline & Full Path $(\beta)$ & T-Statistic & \multicolumn{1}{c|}{ p-value } \\
\hline Perceived Ease of Use $\rightarrow$ Perceived Usefulness $\rightarrow$ Attitude & 0.595 & 16.603 & 0.000 \\
\hline Perceived Ease of Use $\rightarrow$ Attitude $\rightarrow$ Behavioral Intention & 0.103 & 3.924 & 0.000 \\
\hline Perceived Usefulness $\rightarrow$ Attitude $\rightarrow$ Behavioral Intention & 0.324 & 6.992 & 0.000 \\
\hline
\end{tabular}

2 


\section{Table 6 (on next page)}

Table 6: values of R-squared for the model 
Table 6: values of R-squared for the model

\begin{tabular}{|l|c|c|}
\hline & $\mathbf{R}^{\mathbf{2}}$ & $\begin{array}{c}\text { adjusted } \\
\mathbf{R}^{\mathbf{2}}\end{array}$ \\
\hline Attitude & 0.810 & 0.809 \\
\hline Behavioral Intention & 0.769 & 0.767 \\
\hline Perceived Usefulness & 0.716 & 0.716 \\
\hline
\end{tabular}

2 


\section{Table 7 (on next page)}

Table 7: predictive power of latent variables 
Table 7: predictive power of latent variables

\begin{tabular}{|l|r|r|r|}
\hline & RMSE & MAE & Q $^{2}$ _predict \\
\hline Attitude & 0.579 & 0.427 & 0.668 \\
\hline Behavioral Intention & 0.606 & 0.440 & 0.636 \\
\hline Perceived Usefulness & 0.537 & 0.413 & 0.714 \\
\hline
\end{tabular}

2 


\section{Table 8 (on next page)}

Table 8: Multigroup Analysis MGA 
1

Table 8: Multigroup Analysis MGA

\begin{tabular}{|l|l|l|c|c|}
\hline Moderator/ Hypothesis & Path $(\beta)$ & t-statistic & p-value \\
\hline \multirow{5}{*}{ Age } & PR COVID $\rightarrow$ Behavioral Intention & 0.092 & 0.023 & 0.046 \\
\cline { 2 - 5 } & Privacy Concern $\rightarrow$ Behavioral Intention & -0.114 & 0.979 & 0.041 \\
\cline { 2 - 5 } & Perceived Usefulness $\rightarrow$ Behavioral Intention & 0.529 & 0.000 & 0.000 \\
\cline { 2 - 5 } & Trust $\rightarrow$ Behavioral Intention & -0.204 & 0.991 & 0.017 \\
\hline \multirow{3}{*}{ Job } & Privacy Concern $\rightarrow$ Behavioral Intention & -0.131 & 0.989 & 0.022 \\
\cline { 2 - 5 } & Trust $\rightarrow$ Behavioral Intention & -0.237 & 0.998 & 0.004 \\
\hline
\end{tabular}

2 